\title{
Testing Metabolic Theory of Ecology on the local scale: a preliminary study
}

\author{
*Alexia Danyłow, **Werner Ulrich, "Krassimira Ilieva-Makulec, "Izabella Olejniczak, \\ ${ }^{* * *}$ Izabela Hajdamowicz, ${ }^{* * *}$ Marzena Stańska, ${ }^{* * * * *}$ Alexei Uvarov \\ ${ }^{*}$ Centre for Ecological Research - Polish Academy of Sciences, Konopnicka 1, \\ 05-092 Łomianki, Poland,e-mail: a.danylow@cbe-pan.pl \\ **Nicolaus Copernicus University, Faculty of Biology and Environmental Protection, \\ Lwowska 1, 87-100 Torun, Poland, \\ *** University of Natural Sciences and Humanities, Faculty of Sciences, \\ Prusa 14,08-110-Siedlce, Poland, \\ **** Institute for Ecology and Evolution, Russian Academy of Sciences, 33 Leninsky pr., \\ 117071 Moscow, Russia
}

\begin{abstract}
Data on the density and the body mass of a single community of soil fauna were collected and metabolic rates were calculated from the literature data to test some predictions of the metabolic theory of ecology on the local scale. Part of the results are in accordance with the theory: power functions were found between the metabolic rate and the body mass, and between the density and the body mass. These two relationships have opposite exponents inducing that total population energy use is independent of the body mass. However, the exponents of the relationships were significantly different from the predicted values of $|3 / 4|$. The metabolic rate - body mass relationships yielded an exponent $>0.8$, while the density - body mass relationships yielded an exponent $<-0.85$. Our results indicate that the metabolic theory of ecology does not hold at the local level. Few studies have been carried out on the local scale and further analysis is required to validate this controversial but promising theory.
\end{abstract}

Key words: allometric scaling; soil fauna; energy equivalence.

\section{Introduction}

The metabolic theory of ecology, MTE, (Brown et al. 2004 ) is recently one of the most controversially discussed ecological theories (Kozłowski \& Konarzewski 2004; Gillooly et al. 2005; Muller-Landau et al. 2006; van der Meer 2006; Allen et al. 2007; Hawkins et al. 2007; del Rio 2008; Enquist et al. 2009; Price et al. 2012). Developed using first principles of physics, geometry, chemistry and biology, MTE consists of a series of mathematical models that describes the complexities of ecology by showing how metabolic rate controls ecological processes at all levels of organization from individuals to the biosphere (Brown et al. 2004). It is a potentially powerful tool, capable to explain many ecological - in particular macroecological - and evolutionary patterns from a small number of assumptions, such as the optimization of metabolic rates with respect to body size and temperature, or the approximate self-similarity of metabolic active networks of organisms.

The basic equation of the metabolic theory

$$
M \propto W^{3 / 4} e^{-E / k T}
$$

links whole organism metabolic rate $M$ to body weight $W$ and body temperature $T$ ( $E$ denotes the average activation energy of catalytic reactions and $k$ is the Boltzmann's 
constant). Within this equation, the long known three quarter power scaling rule suggested by Kleiber (1932) can be recognized. The temperature term is taken from the Arrhenius equation of chemical reactions. Although equation 1 is derived from a model that strictly applies only to organisms with fractal like supply networks like vertebrates and vascular plants (West et al. 1997, 1999). Brown and co-workers (2004) have found support for this simplistic basic equation over a wide range of organisms from bacteria to invertebrates and higher plants.

Savage et al. (2004) combined equation 1 with Malthusian growth law to develop a model relating species densities $N$ to body weight:

$$
N \infty W^{-3 / 4} e^{E / k T}
$$

Equation 2 therefore predicts that the scaling of population density with body mass is inversely proportional to the scaling of individual metabolic rate (Eq. 1). As a result, the total population energy use $M_{p}$, calculated as the product of individual metabolic rate and population density, is independent of body weight:

$$
M_{p}=M N=\text { const }
$$

This last equation is known as the energy equivalence rule (equal biomass hypothesis in the case of poikilothermic organisms) proposed by Damuth (1987).

A large number of tests was carried out to assess the validity of MTE but the results obtained were mixed (e.g. Meehan 2006; Ulrich 2006; Chown et al. 2007; Downs et al. 2007; Duncan et al. 2007; Hawkins et al. 2007; Sanders et al. 2007; Wang et al. 2009). One of the main questions is whether this theory is universal (i.e. independent of taxon, and spatial and temporal scale), as claimed by its authors. If so, MTE should also hold at the local level and, although developed on vertebrates and plants, should hold for invertebrates. So far, no test has confirmed this claim. Tilman et al. (2004) indicated that body weight data must span at least over four orders of magnitude to allow for good fittings of the MTE model. This explains why no test has been carried out so far at the local scale, where variable ranges are relatively low. The present study intends to verify MTE predictions described above at the local level for soil invertebrates (Nematoda, Enchytraeidae, Collembola, Lumbricidae, Araneae, Diplopoda, Gastropda, Isopoda, Insecta) from a deciduous forest in Central Poland. Working with the soil sub-system enables us to collect data ranging over a few orders of magnitude, both in term of body weight and density, allowing for a good testing of the above equations. More precisely, we hypothesize that:

1 - The natural logarithm of temperature-corrected metabolic rate $(M)$ should be a linear function of the logarithm of body mass $(W)$. The slope of this relationship is predicted to be $3 / 4$ :

$$
\ln \left(M \mathrm{e}^{E / k T}\right)=3 / 4 \ln W+\text { const }
$$

2 - The natural logarithm of a given species density $(N)$, corrected for temperature, should be a linear function of the logarithm of average body mass $(W)$. The slope of this relationship is predicted to be $-3 / 4$ :

$\ln \left(N \mathrm{e}^{-E / k T}\right)=-3 / 4 \ln W+$ const

3 - The total energy flux of a population per unit area $\left(M_{P}\right)$ should be invariant with respect to body mass:

$M_{P}=$ constant

\section{Materials and methods}

The fieldwork was conducted on a rather homogeneous $200 \mathrm{~m}^{2}\left(10 \times 20 \mathrm{~m}^{2}\right)$ plot located on the Eastern border of Kampinos National Park (Poland) close to the village „Dziekanów Leśny” in a 40-50 year-old deciduous forest growing on a podzolic soil. Although collecting the data from a single site introduces the problem of data non-independency, it allows to obtain data related to a single community of interacting individuals.

The soil fauna was sampled in August and October 2009. Samples for different organism groups were collected close to each other in randomly chosen $1 \mathrm{~m}^{2}$ quadrats. Ten replicates were taken for each group. Given that most soil fauna populations are concentrated within the first 5 to $10 \mathrm{~cm}$ of soil (Petersen \& Luxton 1982), the samples were collected to a depth of $10 \mathrm{~cm}$. The nematodes were sampled using a $1.8 \mathrm{~cm}$ diameter corer and were extracted using the Whitehead and Hemming's modification of the Baerman method (Whitehead \& Hemming 1965). The mesofauna was sampled using a $3.5 \mathrm{~cm}$ diameter corer and were extracted using a modified Macfadyen high gradient canister (Macfadyen 1961) in the case of springtails and using the O'Connor modification of the Baerman funnel (O'Connor 1955) in the case of enchytraeids. The macrofauna was hand-sorted from $30 \times 30 \mathrm{~cm}$ samples to a depth of $10 \mathrm{~cm}$. In addition, the surface layer of $50 \times 50 \mathrm{~cm}$ quadrats with $20 \mathrm{~cm}$ high borders thrown from a distance were hand-sorted directly in the field, enabling us to sample fast moving invertebrates that would otherwise escape from our samples. All individuals collected were identified to the species level and density per square meter was calculated for each species.

Body mass was estimated either by direct weighing after drying for $48 \mathrm{~h}$ at $60^{\circ} \mathrm{C}$ in vacuum conditions; or by length and/or width-to-weight regressions. When necessary, fresh-weight/dry-weight ratios were adopted from Persson and Lohm (1977).

The metabolic rate of each individual was derived from the long known relationship between body weights $(W)$ and metabolic rates $(M)$ for specific groups of organisms such as $M=a W^{b}$, where $a$ and $b$ are constants (cf. the detailed discussion in Persson \& Lohm 1977). These parameters were either directly taken from the literature or were calcu- 
Table 1. Parameters used for the calculation of individual metabolic rate $\left(M, \mathrm{~mm}^{3} \mathrm{O}_{2} \mathrm{ind}^{-1} \mathrm{~h}^{-1}\right)$ from fresh individual body mass $(W, \mathrm{~g})$ at $10^{\circ} \mathrm{C}$. The relationships are given in the form $M=a W^{b}$

\begin{tabular}{|c|c|c|c|c|}
\hline Taxon & $\mathbf{a}$ & b & $\mathbf{Q}_{10}$ & $\begin{array}{l}\text { Sources } \\
\text { * Regression calculated on the } \\
\text { basis of data from the quoted sources }\end{array}$ \\
\hline Nematoda & 11.7 & 0.72 & 2.5 & Klekowski et al. 1972 \\
\hline \multicolumn{5}{|l|}{ Collembola } \\
\hline Isotomiella minor & 47.5 & 0.828 & 2 & Petersen 1981 \\
\hline Parisotoma notabilis & 48.68 & 0.8 & 1.9 & $"$ \\
\hline Lepidocyrtus lanuginosus & 101.37 & 0.835 & 2.9 & $"$ \\
\hline Folsomia quadrioculata & 9.5 & 0.669 & 2.2 & $"$ \\
\hline Pogonognathellus flavescens & 260.64 & 0.963 & 5.2 & $"$ \\
\hline other collembolan & 64.77 & 0.85 & 2.6 & $\begin{array}{l}\text { * Ehnes } 2011 \\
\quad\left(\mathrm{n}=128 ; \mathrm{r}^{2}=0.85\right)\end{array}$ \\
\hline \multicolumn{5}{|l|}{ Mesostigmata } \\
\hline Gamasina & 102.33 & 0.869 & 3 & Wood and Lawton 1973 \\
\hline Uropodina & 5.035 & 0.671 & 3 & " \\
\hline Enchytraeidae & 18.67 & 0.67 & 1.6 & Persson and Lohm 1977 \\
\hline \multicolumn{5}{|l|}{ Lumbricidae } \\
\hline Aporrectodea caliginosa & 41.8 & 0.91 & 2 & Byzova 2007 \\
\hline Dendrobaena octaedra & 63.8 & 0.71 & 2 & $"$ \\
\hline Lumbricus rubellus & 49.84 & 0.84 & 2 & $"$ \\
\hline \multicolumn{5}{|l|}{ Diplopoda } \\
\hline Polydesmus complanatus & 52.28 & 0.79 & 2.5 & $"$ \\
\hline other diplopoda & 18.4 & 0.69 & 2.5 & $"$ \\
\hline Chilopoda & 22 & 0.64 & 2.5 & $"$ \\
\hline Isopoda & 31.1 & 0.63 & 2.15 & $"$ \\
\hline Araneae & 44.57 & 0.68 & 2 & $\begin{array}{l}\text { * Byzova 2007; Ehnes } 2011 \\
\left(\mathrm{n}=395 ; \mathrm{r}^{2}=0.71\right)\end{array}$ \\
\hline \multicolumn{5}{|l|}{ Gastropoda } \\
\hline Deroceras agreste & 188.8 & 0.85 & 1.95 & Byzova 2007 \\
\hline Arion fasciatus & 221.5 & 0.75 & 1.95 & $"$ \\
\hline Punctum pygmaeum & 0.3 & 0.65 & 1.69 & Mason 1971 \\
\hline Vitrina pellucida & 0.3 & 0.65 & 2.01 & $"$ \\
\hline Fruticicola fruticum & 0.3 & 0.65 & 2.21 & $"$ \\
\hline Oxychilidae & 0.3 & 0.65 & 2.37 & $"$ \\
\hline \multicolumn{5}{|l|}{ Coleoptera } \\
\hline Larvae & 77.9 & 0.61 & 2 & $*$ Byzova $2007\left(n=37 ; r^{2}=0.43\right)$ \\
\hline Carabidae & 93.4 & 0.86 & 2 & $\begin{array}{l}\text { * Byzova 2007; Makarieva et al. 2008; } \\
\text { Persson and Lohm 1977; Ehnes } 2011 \\
\left(\mathrm{n}=1014 ; \mathrm{r}^{2}=0.74\right)\end{array}$ \\
\hline Staphylinoidea & 91 & 0.81 & 2 & $\begin{array}{l}\text { * Byzova 2007; Makarieva et al. 2008; } \\
\text { Persson and Lohm 1977; Ehnes } 2011 \\
\left(\mathrm{n}=66 ; \mathrm{r}^{2}=0.82\right)\end{array}$ \\
\hline Scarabaeoidea & 74.55 & 0.64 & 2 & $\begin{array}{l}\text { * Makarieva et al. } 2008 \\
\left(\mathrm{n}=29 ; \mathrm{r}^{2}=0.69\right)\end{array}$ \\
\hline other coleopterans & 98.39 & 0.84 & 2 & $\begin{array}{l}\text { * Makarieva et al. } 2008 \\
\left(\mathrm{n}=159 ; \mathrm{r}^{2}=0.79\right)\end{array}$ \\
\hline Diptera larvae & 135.28 & 0.788 & 2.25 & $\begin{array}{l}\text { * Persson \& Lohm 1977; Byzova } 2007 \\
\left(\mathrm{n}=24 ; \mathrm{r}^{2}=0.87\right)\end{array}$ \\
\hline Blattodae & 77.76 & 0.87 & 2 & $\begin{array}{l}* \text { Makarieva et al. } 2008 \\
\left(\mathrm{n}=14 ; \mathrm{r}^{2}=0.93\right)\end{array}$ \\
\hline Heteroptera & 84.5 & 0.62 & 2 & $\begin{array}{l}\text { * Makarieva et al. } 2008 \\
\left(\mathrm{n}=11 ; \mathrm{r}^{2}=0.69\right)\end{array}$ \\
\hline other insects & 113.14 & 0.82 & 2 & Makarieva et al. 2008 \\
\hline
\end{tabular}


lated from literature data, using reduced major axis regression (RMA) (Table 1). We adjusted to field temperatures using $\mathrm{Q}_{10}$ values. Temperature data were collected from the closest meteorological station of Kampinos National Park (Izabelin).

In order to test the first hypothesis, regarding the relationship between metabolic rate $(M)$, body mass $(W)$ and temperature $(T)$, regressions of the form $\ln \left(M \mathrm{e}^{E / k T}\right)=\delta \ln$ $W+a$ were run on $\ln$-transformed data. The parameter $\delta$ was expected to equal 3/4. Body weight (g FW) and whole organism metabolic rate $\left(\mathrm{mm}^{3} \mathrm{O}_{2}\right.$ ind $\left.^{-1} \mathrm{~h}^{-1}\right)$ were averaged per species. The second hypothesis, relating population density $(N)$ to body mass, was tested by performing regressions of the type $\ln \left(\mathrm{Ne}^{-E / k T}\right)=\beta \ln W+a$ on $\ln$-transformed data. The parameter $\beta$ was expected to equal $-3 / 4$. Density referred to the number of individuals per square meter. In both cases temperature values used corresponded to the 30 day average preceding the sampling date. The value of 0.65 $\mathrm{eV}$ was taken as the average activation energy $(E)$ of catalytic reactions (Gillooly et al. 2001). The third hypothesis, stating that population energy use $\left(M_{p}\right)$ is invariant with body mass, was evaluated in two ways. First we checked whether there was a correlation between both parameters. Second we checked whether the sum of the slopes calculated for the two first hypotheses was close to zero.

Each sampling date (August 2009 and October 2009) was considered separately. Correlation and regression analyses were performed on ln-transformed data using Past (Hammer et al. 2001). As advised by Griffiths (1992), regression slopes refer to reduced major axis (RMA) slopes.

\section{Results}

A total number of 1651 and 1680 individuals belonging to 127 and 122 species were collected in August 2009 and October 2009 respectively. The total biomass was $4.55 \pm 2.09 \mathrm{~g}$ $\mathrm{FWm}^{-2}$ in August 2009 and $2.72 \pm 1.43 \mathrm{~g} \mathrm{FWm}^{-2}$ in October 2009. Body mass covered eight orders of magnitude, ranging from $5.09 \times 10^{-9} \mathrm{~g} \mathrm{FW}$ (Eucephalobus sp.1- Nematoda) to $0.28 \mathrm{~g} \mathrm{FW}$ (Aporrectodea caliginosa - Lumbricidae) in August 2009 and from $8.6 \times 10^{-9}$ g FW (Aphelenchoides sp.1- Nematoda) to 0.51 g FW (Arion fasciatus - Gastropoda) in October 2009. The most abundant species was the nematode Aphelenchoides sp.1 (1,871,642 ind. $\mathrm{m}^{-2}$ in August 2009 and 1,369,966 ind. $\mathrm{m}^{-2}$ in October 2009), while the least abundant species were carabid beetles $\left(<1\right.$ ind. $\left.\mathrm{m}^{-2}\right)$. The density ranged six orders of magnitude.

As expected, a strong positive correlation (Fig. 1) was found between individual metabolic rate and body mass for both data sets $\left(r^{2}=0.99 ; p=0.0001\right)$. However, the RMA slopes significantly differed from the expected $3 / 4$ value (95\% CI: 0.82;0.85 and 0.84;0.87 respectively). Similarly, the density - body mass relationship (Fig. 2) can be described by a power function, since a strong correlation has been found for the ln-transformed data $\left(\mathrm{r}^{2}=0.85\right.$ and 0,82 ; $\mathrm{p}=0.0001$ ) but once again the RMA slopes significantly deviated from the predicted value of $-3 / 4$ (95\% CI: -0.92 ; -0.81 and $-0.95 ;-0.83)$.

Figure 3 shows that there was no significant relationship between body mass and total energy use $(p=0.31$ and 0.16$)$,

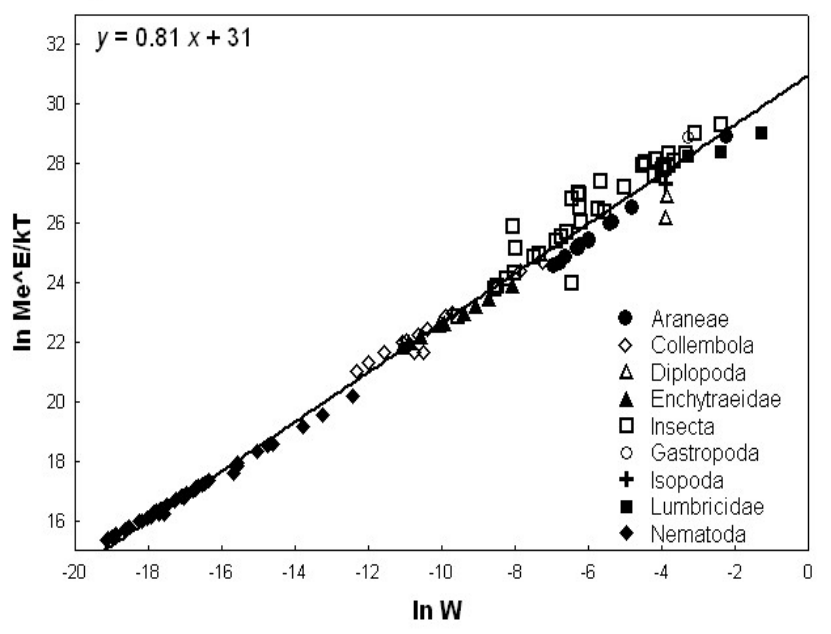

B



Figure 1. Relationship between temperature-corrected metabolic rate, $\ln \left(\mathrm{Me}^{\wedge} \mathrm{E} / \mathrm{kT}\right)$ and body weight, $\ln \mathrm{W}$ (g FW). (A) Animals collected in August 2009. $\mathrm{r}^{2}=0.99 ; \mathrm{p}=0.0001 ; \mathrm{N}=127$. The slope significantly differs from the predicted $3 / 4$ ( $95 \% \mathrm{CI}$ : $0.82 ; 0.85)$. (B) Animals collected in October 2009. $\mathrm{r}^{2}=0.99 ; \mathrm{p}=0.0001 ; \mathrm{N}=122$. The slope significantly differs from the predicted 3/4 (95\%CI: 0.84;0.87) 

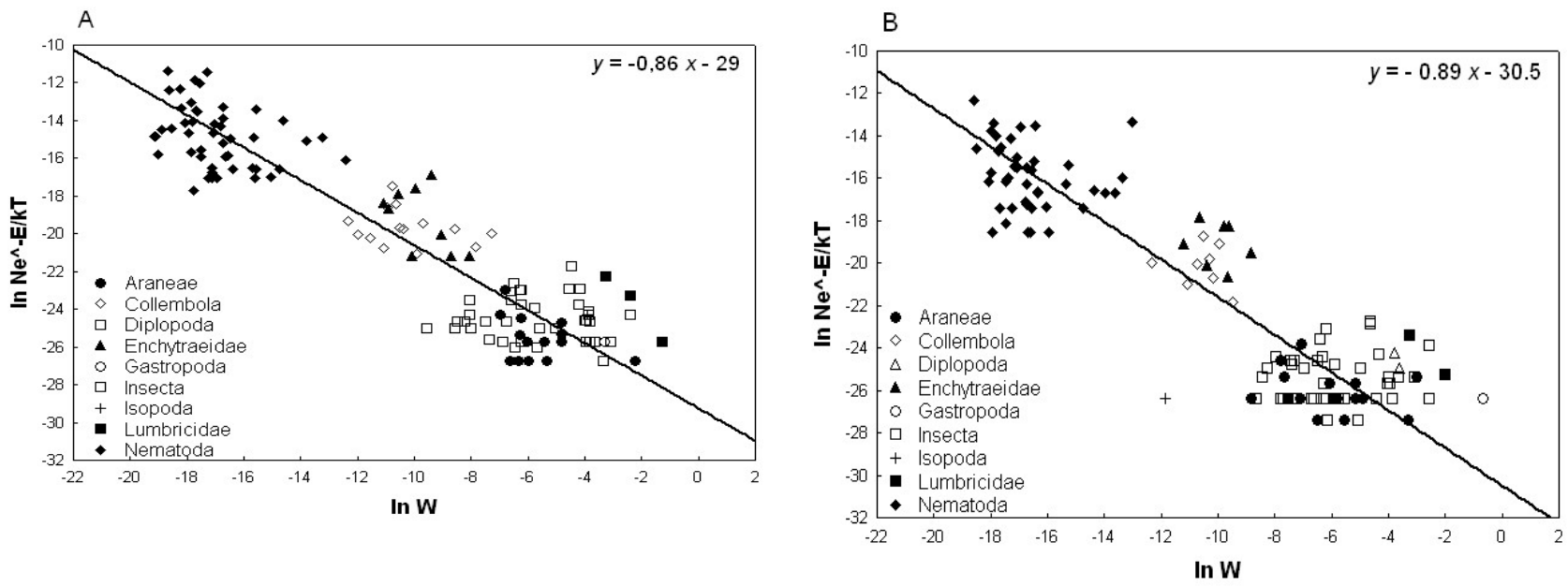

Figure 2. Relationship between temperature-corrected density, $\ln \left(\mathrm{Ne}^{\wedge}-\mathrm{E} / \mathrm{kT}\right)$ and body weight, $\ln \mathrm{W}(\mathrm{g} F \mathrm{~F})$. (A) Animals collected in August 2009. $\mathrm{r}^{2}=0.85 ; \mathrm{p}=0.0001 ; \mathrm{N}=127$. The slope significantly differs from the predicted $3 / 4(95 \% \mathrm{CI}:-0.92 ;-0.81)$.

(B) Animals collected in October 2009. $\mathrm{r}^{2}=0.82 ; \mathrm{p}=0.0001 ; \mathrm{N}=122$. The slope significantly differs from the predicted $3 / 4$ (95\%CI: $-0.95 ;-0.83$ )
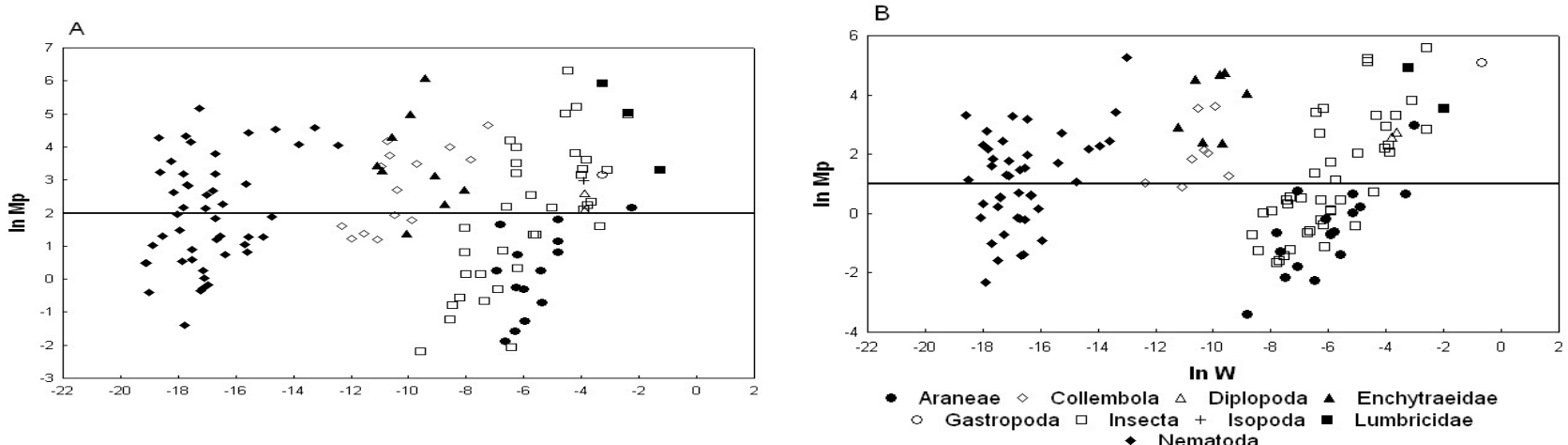

Figure 3. Relationship between total population energy use, $\ln \mathrm{Mp}$ and body weight, $\ln \mathrm{W}$ (g FW). (A) Animals collected in August 2009. $r^{2}=0.01 ; p=0.31 ; N=127$. (B) Animals collected in October 2009. $r^{2}=0.02 ; p=0.16 ; N=122$

and the sums of the slopes of equation 1 and 2 were found to be close to zero $(-0.031 \pm 0.031$ and $-0.03028 \pm 0.035$ respectively), as predicted by equation 3 . These results are in agreement with the energy equivalence rule.

\section{Discussion}

The aim of the present study was to test some predictions of the metabolic theory of ecology (eq. 1 to 3 ) at the local scale on invertebrates. MTE has so far been tested mostly at wide scales, using data compiled from different studies and spanning up to 21 orders of magnitude (Brown et al 2004). One can wonder whether this theory is applicable at the local scale where variable ranges are comparatively narrow. Besides, MTE has been developed on vertebrates and vascular plants (West et al. 1997, 1999) and some doubts have been expressed on whether these models can be applied to invertebrates (Kozłowski \& Konarzewski 2004, 2005).

The present study is, to some extent, is accordance with MTE. The metabolic rate and density - body weight relationships were power functions with exponents having the correct sign, and no dependence was found between total population energy use and body weight. However, at the quantitative level, the slopes differed from the predicted values. There has been some debate over the correct value of the exponent of the metabolic rate - body weight scaling (Isaac \& Carbone 2010). While the MTE's authors predict $3 / 4$, others claim it to $2 / 3$ as predicted by classical Euclidean geometry from the consideration of surface/ volume ratio (Dodds et al. 2001; White \& Seymour 2003). The slopes obtained in this study were steeper than $3 / 4$ (Fig. 1), rejecting both predictions. Brown et al. 2004 indicated that the exponent of this relationship should not necessarily equal $3 / 4$ but exhibit a close value. In our case, 
the slopes obtained are almost a point higher than expected. This suggests that the scaling between metabolic rate and body weight does not take any particular value but vary among organisms. Similarly, the slopes found for the density - body weight relationship were steeper than predicted by equation 2 (Fig. 2). This came as a surprise since many studies carried out at the level of a single community found shallower slope than $-3 / 4$ (c.f. Blackburn et al 1993). However, studies carried out at a wider scale often found a slope steeper than -3/4 (c.f. Blackburn \& Gaston 1997). Our results may be explained by the fact that the data ranged over many orders of magnitude, reducing the noise inherent to small data bases.

As predicted by MTE, the exponents of equations 1 and 2 were found to have opposite values. As a result, total population energy per unit area is independent of body weight (Fig. 3). It would seem that this last model holds both at the local level and for invertebrates.

The present study found some qualitative supports to the metabolic theory of ecology, yet the parameter values were found to differ from the predicted ones at the local level and for invertebrates. While the specific values are questionable, the basic scaling rules and the evolutionary optimization argument remain undisputed and provide a good starting point for further analysis (del Rio 2008). This work was a short one and more data are necessary to allow for a sound testing of MTE. If its predictions are supported by future data, theoreticians will have a better ground to improve this controversial but promising theory.

\section{Acknowledgement}

We would like to thank the specialists for the identifications of some animal groups: Dawid Marczak (Insecta), Vladimir Semionov (Staphylinidae), Anatoly Shileyko (Gastropoda) and Sergei Golovatch (Diplopoda).

\section{References}

Allen A. P., Gillooly, J. F. \& Brown, J. H., 2007, Recasting the species-energy hypothesis: the different roles of kinetic and potential energy in regulating biodiversity, [in:] D. Storch, P. A. Marquet, J. H. Brown (eds.), Scaling Biodiversity, Cambridge University Press, Cambridge: 283-299.

Blackburn T. M., Brown V. K., Doube B. M., Greenwwod J. J. D., Lawton J. H. \& Stork N. E., 1993, The relationship between abundance and body size in natural animal assemblages, Journal of Animal Ecology 62: 519-528.

Blackburn T. M. \& Gaston K. J., 1997, A critical assessment of the form of the interspecific relationship be- tween abundance and body size in animals, Journal of Animal Ecology 66: 233-249.

Brown J. H., Gillooly J. H., Allen A. P., Savage V. M. \& West G. B., 2004, Towards a metabolic theory of ecology, Ecology 85: 1771-1789.

Byzova Y. B., 2007, Respiration of soil invertebrates, KMK Publishing House, Moscow: 328. (In Russian).

Chown S. L., Marais E., Terblanche J. S., Klok C. J., Lighton J. R. B. \& Blackburn T. M., 2007, Scaling of insect metabolic rate is inconsistent with the nutrient supply network model, Functional Ecology 21: 282-290.

Damuth J., 1987, Interspecific allometry of population density in mammals and other animals: the independence of body mass and population energy-use, Biological Journal of the Linnean Society 31: 193-246.

Del Rio C. M., 2008, Metabolic theory or metabolic models?, Trends in Ecology and Evolution 23: 256-260.

Dodds P. S., Rothman D. H. \& Weitz J. S., 2001, Re-examination of the "3/4-law" of metabolism, J. Theor. Biol. 209: 9-27.

Downs C. J., Hayes J. P. \& Tracy C. R., 2007, Scaling metabolic rate with body mass and inverse body temperature: a test of the Arrhenius fractal supply model, Functional Ecology 22: 239-244.

Duncan R. P., Forsyth D. M. \& Hone J., 2007, Testing the metabolic theory of ecology: Allometric scaling exponents in mammals, Ecology 88: 324-333.

Enquist B. J., West G. B. \& Brown J. H., 2009, Extensions and evaluation of a general quantitative theory of forest structure and dynamics, Proc. Nat. Acad. of Sci. USA 106: 7046-7051.

Gillooly J. F., Brown J. H., West G. B., Savage Van M. \& Charnov E. L., 2001, Effects of size and temperature on metabolic rate, Science 293: 2248-2251.

Gillooly J. F., Allen A. P., West G. B. \& Brown J. H., 2005, The rate of DNA evolution: effects of body size and temperature on the molecular clock, Proc. Natl. Acad. Sci. USA 102: 140-145.

Griffiths D., 1992, Size, abundance, and energy use in communities, Journal of Animal Ecology 61: 307-315.

Hammer Ř., Harper D. A. T. \& Ryan P. D., 2001, PAST: Paleontological Statistics Software Package for Education and Data Analysis, Palaeontologia Electronica 4(1), http://palaeo-electronica.org/2001_1/past/issue1_01.htm

Hawkins B. A., Albuquerque F. S., Araujo M. B., Beck J., Bini L. M., Cabrero-Sañudo F. J., Castro-Parga I., Diniz-Filho J. A., Ferrer-Castan D., Field R., Gómez J. F., Hortal J., Kerr J. T., Kitching I. J., León-Cortés J. L., Lobo J. M., Montoya D., Moreno J. C., Olalla-Tárraga M. A., Pausas J. G., Qian H., Rahbek C., Rodríguez M. A., Sanders N. J. \& Williams P., 2007, A global evaluation of metabolic theory as an explanation for terrestrial species richness gradients, Ecology 88: 1877-1888. 
Isaac N. J. B. \& Carbone C., 2010, Why are metabolic scaling exponents so controversial? Quantifying variance and testing hypotheses, Ecological Letters 1: 728-735.

Kleiber M., 1932, Body size and metabolism, Hilgardia 6: $315-332$.

Klekowski R. Z., Wasilewska L. \& Paplińska E., 1972, Oxygen consumption by soil-inhabiting nematodes, Nematologica 18: 391-403.

Kozłowski J. \& Konarzewski M., 2004, Is West, Brown and Enquist's model of allometric scaling mathematically correct and biologically relevant?, Functional Ecology 18: 283-289.

Kozłowski J. \& Konarzewski M., 2005, West, Brown and Enquist's model of allometric scaling again: the same question remain?, Functional Ecology 19: 739-743.

Macfadyen A., 1961, Improved funnel-type extractors for soil arthropods, Journal of Animal Ecology 30: 171184.

Makarieva A. M., Gorshkov V. G., Li B. L., Chown S. L. \& Reich P. B., 2008, Mean mass-specific metabolic rates are strikingly similar across life's major domains: Evidence for life's metabolic optimum, Proc. Natl. Acad. Sci. USA 105: 16994-16999.

Mason C. F., 1971, Respiration rates and population metabolism of woodland snails, Oecologia 7: 80-94.

Meehan T. D., 2006, Energy use and animal abundance in litter and soil communities, Ecology 87: 1650-1658.

Muller-Landau H. C., Condit R. S., Chave J., Thomas S. C., Bohlman S. A., Bunyavejchewin S., Davies S., Foster R., Gunatilleke S., Gunatilleke N., Harms K. E., Hart T., Hubbell S. P., Itoh A., Kassim A. R., LaFrankie J. V., Lee H. S., Losos E., Makana J. R., Ohkubo T., Sukumar R., Sun I. F., Nur Supardi M. N., Tan S., Thompson J., Valencia R., Muñoz G. V., Wills C., Yamakura T., Chuyong G., Dattaraja H. S., Esufali S., Hall P., Hernandez C., Kenfack D., Kiratiprayoon S., Suresh H. S., Thomas D., Vallejo M. I. \& Ashton P., 2006, Testing metabolic ecology theory for allometric scaling of tree size, growth and mortality in tropical forests, Ecology Letters 9: 575-588.

O'Connor F. B., 1955, Extraction of enchytraeid worms from a coniferous forest soil, Nature 175: 815-816.
Persson T. \& Lohm U., 1977, Energetical significance of the annelids and arthropods in a Swedish grassland soil, Ecological Bulletins 23: 1-211.

Petersen H., 1981, The respiratory metabolism of Collembola species from a Danish beech wood, Oikos 37: 273-286.

Price C. A., Weitz J. S., Savage V. M., Stegen J., Clarke A., Coomes D. A., Dodds P. S., Etienne R. S., Kerkhoff A. J., McCulloh K., Niklas K. J., Olff H. \& Swenson N. G., 2012, Testing the metabolic theory of ecology, Ecology Letters 15: 1465-1474.

Sanders N. J., Lessard J.-P., Fitzpatrick M. C. \& Dunn R. R., 2007, Temperature, but not productivity or geometry, predicts elevational diversity gradients in ants across spatial grains, Global Ecology \& Biogeography 16: 640-649.

Savage V. M., Gillooly J. F., Brown J. H., West G. B. \& Charnov E. L., 2004, Effects of Body Size and Temperature on Population Growth, Am. Nat. 163: 429-441.

Tilman D., Lambert J. H. R., Harploe S., Dybzinski R., Fargione J., Clarke C. \& Lehman C., 2004, Does metabolic theory apply to community ecology? It's a matter of scale, Ecology 85: 1797-1799.

Ulrich W., 2006, Metabolic theory at the local scale: the case of the Hymenoptera, Ecological Questions 7: 9-14.

van der Meer J., 2006, Metabolic theories in ecology, Trends in Ecology and Evolution 21: 136-140.

Wang X., Hao Z., Zhang J., Lian J., Li B. \& Yao X., 2009, Tree size distributions in an old-growth temperate forest, Oikos 118: 25-36.

West G. B., Brown J. H. \& Enquist, B. J., 1997, A general model for the origin of allometric scaling laws in biology, Science 276: 122-126.

West G. B., Brown J. H. \& Enquist B. J., 1999, A general model for the structure and allometry of plant vascular systems, Nature 400: 664-667.

White C. R. \& Seymour R. S., 2003, Mammalian basal metabolic rate is proportional to body mass (2/3), Proc. Natl. Acad. USA 100: 4046-4049.

Whitehead A. G. \& Hemming J. R., 1965, A comparison of some quantitative methods of extracting small vermiform nematodes from soil, Annals of Applied Biology 55: 25-38. 
